\title{
"MODEL KERJA SAMA PEMERINTAH KOTA BANJARMASIN DALAM TATA KELOLA LINGKUNGAN LAHAN BASAH"
}

\author{
NOR ASIAH - A
}

Para peneliti melakukan penelitian ini untuk mengkaji kerangka model kerjasama sister city yang akan dilakukan oleh pemerintah kota Banjarmasin dalam tata kelola lingkungan lahan basah atau wetland governance. Model kerjasama ini masyarakat merupakan cara baru yang menarik untuk menyelesaikan permasalahan lingkungan lahan basah di Banjarmasin. Model pengelolaan lingkungan lahan basah ini ialah pengelolaan lingkungan lahan basah terpadu, Oleh karena itu, kebijakan ini adalah bagian yang tidak terpisahkan dari kebijakan lingkungan hidup berdasarkan data akademik dan teknis. selama model kerja sama yang sudah diterapkan di anggap kurang memperhatikan aspek-aspek yang mengintegrasikan Lembaga teknologi dan pendanaan. Upaya pengelolaan lingkungan persawahan yang dapat dilakukan oleh pemerintah jika dibantu oleh masyarakat tentunya akan mendapatkan hasil yang optimal. Inti dari keberhasilan kerjasama ini adalah adanya tanggung jawab, keputusan, dan tindakan nyata untuk pengelolaan lingkungan lahan basah. Semuanya ditanggung bersama oleh pemerintah kota (pemkot) dan warga. Implementasi model kerjasama ini terletak pada upaya pemerintah kota dan masyarakatnya. Pemerintah kota berperan sebagai penyedia dalam memantau kawasan prioritas penataan lingkungan lahan basah dan memberikan pembinaan kepada warga. Di dalam model kerja sama bottom up tersebut masyarakat diminta untuk aktif dalam proses perumusan dan proses implementasi kerja sama. Pada prinsipnya kebijakan pengelolaan lingkungan lahan basah secara terpadu merupakan hal yang sangat penting dalam rangka mengurangi dan menghadapi permasalahan sumberdaya alam baik dari segi kualitas dan kuantitasnya. Meskipun terdapat beberapa kelemahan dalam model ini khususnya memerlukan banyak waktu dan tenaga dalam perencanaannya tetapi harapannya hasilnya bisa lebih efektif dalam penanggulangan lingkungan lahan basah. Model kerja sama sister city bottom up kemudian dibuat berdasarkan banjir yang terjadi di Samarinda, Seluruh kerja sama ini telah menjadi ketergantungan kolektif kota (kotamadya) dan penduduk (resident). Pengelolaan model ini kolaborasi terletak pada upaya kota dan warganya. Pemerintah kota bertindak sebagai penyedia dalam melakukan pengawasan daerah banjir dan memberikan konstruksi kepada orang-orang. Kesiapsiagaan, ketangguhan dan partisipasi aktif dari masyarakat sangat penting dalam menghadapi banjir. Hasilnya dapat dipahami karena manusia adalah bagian korban bencana, sehingga menimbulkan semangat dan motivasi yang tinggi untuk bertindak dan memperjuangkan bencana yang mereka hadapi di wilayah mereka. Bencana dapat disebabkan oleh alam (natural disaster) maupun karena ulah manusia. Permasalahan yang akan muncul terkait dengan cara penanggulangan bencana terutama upaya untuk mengatasi dan meminimalkan bencana yang berkurang dengan menjalin kerjasama luar negeri sister city. Hasil tersebut dapat dipahami karena masyarakat merupakan bagian dari korban bencana, agar memiliki semangat dan motivasi yang tinggi untuk bertindak dan berusaha dalam penanggulangan bencana itu mereka hadapi di daerah mereka.Penulis benar-benar memperhatikan hambatan dan keterbatasan pemeriksaan pendekatan yang dihasilkan untuk artikel ini namun secara bersamaan yakin perlunya mengarahkan dialog di bidang ini. Studi masa depan harus diperluas ke Indonesia yang lebih luas atau wilayah Asia Tenggara sehingga temuannya dapat digeneralisasikan. 


\section{REFERENCES}

Al Syahrin, M. N., Mahyuni, A., Sompa, A. T., Jamaluddin, A. I., Budhi, S., Rachman, D., \& Alunaza, H. (2019). BOTTOM-UP MODEL ANALYSIS OF COMMUNITY INVOLVEMENT IN THE SISTER CITY COOPERATION FOR FLOOD MITIGATION IN EAST KALIMANTAN.

Al Syahrin, M. N., Mahyuni, M., Apriansyah, A., Sompa, A. T., Jamaluddin, J., Asmu'i, A., ... \& Alunaza, H. (2020). Bottom-Up Model Analysis of Community Involvement in the Sister City Cooperation for Flood Mitigation in East Kalimantan. Revista UNISCI/UNISCI Journal, (53), 143-156.

Al Syahrin, M. N., Mahyuni, T. T., Riyadi, H., \& Rahmah, A. (2021). MODEL RANCANGAN KERJA SAMA SISTER CITY KOTA KEMBAR BANJARMASIN DALAM TATA KELOLA LINGKUNGAN LAHAN BASAH (WETLAND GOVERNANCE). In PROSIDING SEMINAR NASIONAL LINGKUNGAN LAHAN BASAH (Vol. 6, No. 3).

Al Syahrin, M. Najeri, Apriansyah Mahyuni, Andi Tenri Sompa, Asmu'I. Jamaluddin, Setia Budhi, Dzul Rachman, and Hardi Alunaza. "BOTTOM-UP MODEL ANALYSIS OF COMMUNITY INVOLVEMENT IN THE SISTER CITY COOPERATION FOR FLOOD MITIGATION IN EAST KALIMANTAN." (2019).

Al Syahrin, M. Najeri, M. Mahyuni, A. Apriansyah, Andi Tenri Sompa, J. Jamaluddin, A. Asmu'i, Setia Budhi, Dzul Rachman, and Hardi Alunaza. "Bottom-Up Model Analysis of Community Involvement in the Sister City Cooperation for Flood Mitigation in East Kalimantan." Revista UNISCI/UNISCI Journal 53 (2020): 143-156.

Al Syahrin, M. Najeri, Terry Tabitha Mahyuni, Husama Riyadi, and Anisa Rahmah. "MODEL RANCANGAN KERJA SAMA SISTER CITY KOTA KEMBAR BANJARMASIN DALAM TATA KELOLA LINGKUNGAN LAHAN BASAH (WETLAND GOVERNANCE)." In PROSIDING SEMINAR NASIONAL LINGKUNGAN LAHAN BASAH, vol. 6, no. 3. 2021.

Mahyuni, M., \& Syahrin, M. N. (2021). Sister City Cooperation Model In Wetland Environmental Governance: Case Study In Banjarmasin, South of Kalimantan. International Journal of Politic, Public Policy and Environmental Issues, 1(02), 115-125.

Mahyuni, Mahyuni, and Muhammad Najeri Syahrin. "Sister City Cooperation Model In Wetland Environmental Governance: Case Study In Banjarmasin, South of Kalimantan." International Journal of Politic, Public Policy and Environmental Issues 1, no. 02 (2021): 115-125.

Syahrin, M. N. A., Rukmana, G. M., Rachman, D., Harakan, A., \& Tadjine, F. (2019). Sister city bottom up collaborative model plan as a major flooding mitigation in Samarinda.

Syahrin, Muhammad Najeri Al, Gilang Mukti Rukmana, Dzul Rachman, Ahmad Harakan, and Farida Tadjine. "Sister city bottom up collaborative model plan as a major flooding mitigation in Samarinda." (2019). 